\title{
Another Look at the Distribution of Physicians \#
}

\author{
G. Donald Jud AND JefFrey L. HarRison*
}

Health economists have been concerned for some time with the numbers and distribution of the various classes of health manpower. Although this concern has been stated largely in terms of shortages of all types of manpower, the distribution of physicians has been emphasized because of their roles as deliverers of final health services as well as managers of other resources involved in the provision of health and medical care. Previous studies which have sought to explain the factors influencing the location of physicians have typically been plagued by two problems. First, reliable data on physicians' incomes on a state-by-state basis have not been available. ${ }^{1}$ Secondly, there has been an incomplete theoretical specification of the factors determining the location of physicians. As a result, previous studies have generally reached conflicting conclusions with regard to the magnitude and direction of forces relevant to the spatial distribution of physician manpower.

The first section of this study presents a brief review of the literature dealing with the spatial distribution of physicians. The focus is particularly on the areas in which conflicting results have been presented in the past. The second section presents an empirical investigation of the factors influencing the location of physicians, utilizing earnings data only recently available. ${ }^{2}$ The empirical section involves a double focus. First, a methodological framework typically used in studies of this nature is employed. Second, a new methodology is utilized which is appropriate owing to the unique nature of the physician in determining the quantity of his services both supplied and demanded. The final section summarizes the findings and discusses the health manpower policy implications.

\section{Previous Research}

Physicians, like other groups of professional workers, base their locational decisions upon a wide range of factors-cultural and recreational opportunities, professional opportunities, family ties, and expected income. Previous studies of the spatial distribution of physicians have focused upon economic factors and certain other variables which are subject to broad policy control. However, these earlier studies have presented results from which it is difficult to derive clear implications relevant to the determinants of physicians' locational decisions. Three studies representative of typical results reported by researchers in this area include studies by Henry B. Steele and Gaston V. Rimlinger [19], L. Benham, A. Maurizi, and M. W. Reder [3], and R. M. Scheffler [17]. Variables common to two or

\#A preliminary version of this paper was presented at the Southern Economics Association meetings in Houston, Texas on November 8, 1973. The authors would like to thank Professor Henry B. Steele (University of Houston) for helpful comments and suggestions on this earlier version of the paper. Also, the authors are indebted to Mr. John Redmond and Mr. Louis Rios for their assistance in collecting and compiling statistical information.

*Associate Professors of Economics, Department of Economics, University of North Carolina at Greensboro, Greensboro, North Carolina. 
more of these studies are average physicians' earnings, per capita personal income, population, degree of urbanization, barriers to entry, and certain proxy variables for professional amenities-the availability of physician training facilities and the availability of hospital beds.

\section{Physician Earnings}

One of the major areas of disagreement has been the relationship between the distribution of physicians and average physicians' income. This has almost certainly resulted from the absence of reliable income data. Using 1949 SMSA data, Steele and Rimlinger concluded that physicians were not induced to locate on the basis of higher than average physicians' earnings. Benham et al. found this not to be the case. In their 1968 study, the authors reported that changes in medics' incomes were negatively associated with the changes in the physicianpopulation ratio of a state. While the authors did not explicitly define medics' incomes, they expressed strong reservations with regard to the quality of these data. Their findings conformed to the theoretical expectations that physicians per capita would increase in those states where physicians earnings are high and that this movement would precipitate a fall in physicians' earnings. Further support was found through the estimation of a two-stage least squares model in which a proxy variable for physicians' earnings was used as an independent variable in the supply equation. The supply of self-employed physicians was found to be positively related to average medics' income.

\section{Area Per Capita Income}

Steele and Rimlinger found, as have most researchers, that physicians tend to be concentrated in high per capita income areas. However, they were not able to separate the independent effects of income and urbanization. They reported a strong per capita income-urbanization interaction resulting in a positive relationship between changes in per capita income and changes in the number of physicians in only metropolitan areas. The authors were reluctant to claim statistical significance in the case of this urban specific phenomenon.

Benham et al. found a highly significant relationship between per capita income and per capita number of physicians. But, statistically significant relationships were not found between either initial per capita income or changes in per capita income and the per capita number of physicians. In their two-stage least squares model, the authors reported per capita income to be a strong determinant of the demand for physician services.

In a 1972 study, Scheffler found little to suggest a statistically significant relationship between per capita income and the physician population ratio. While this seems to conflict with the findings of earlier studies, it should be noted that the authors reported that the effects of income and urbanization could not be separated and that a serious problem of multicollinearity existed.

\section{Population}

While population, per se, is of little interest as a determinant of the total number of physicians, Steele and Rimlinger and Benham et al. included it in their 
studies and found the expected highly significant relationship between population and the total number of physicians in a state. In addition, Benham et al. reported that the number of physicians responded proportionately to changes in population. This would indicate that the effect of population is neutral and that the relevant relationships should be estimated on a per capita basis. Steele and Rimlinger indicate that the close relationship between population and number of physicians is really a function of the mobility of physicians as a group rather than as individuals. In other words, individual physicians do not migrate from state to state but general mobility is afforded through entry into and exit from the profession. Benham et al. [3, p. 337] offer a different explanation. They state, “... interstate migrants (roughly) bring their own medics to care for them. This occurs despite well-known obstacles to mobility...."

\section{Urbanization}

Despite problems of multicollinearity among urbanization, per capita income, and population, the degree of urbanization has generally been found to exert a positive influence on the per capita number of physicians. One possible exception to this was reported by Benham et al. Using an ordinary least squares estimate the researchers found that the percentage of population living in areas of more than 2,500 persons did not appear to influence the per capita availability of physicians. Yet, in their two-stage least squares model, the authors reported that urbanization did influence the supply of physicians' services.

Steele and Rimlinger found that physicians tended to locate in more urban areas. Particularly interesting is that the authors found the drawing power of increases in per capita income and population to be relatively stronger in urban as opposed to rural areas.

Finally, Scheffler found that urbanization is positively related to the per capita availability of surgical specialists, medical specialists, residents and interns, and negatively related to the per capita availability of general practitioners. In all cases the relationships were statistically significant.

\section{Barriers to Entry}

Benham et al. and Scheffler attempted to include some measure of the influence of various barriers to practice on the distribution of physicians. Both studies used the percentage of applicants failing the licensure examination as the measure of the relative strength of these barriers. While the researchers were generally aware of the weaknesses of this measure, it may, in fact, be a good proxy for the attitudes of the various states with respect to entry. However, using the same measure, the researchers reached conflicting conclusions. Benham et al. found a statistically significant positive relationship between failure rates and the number of physicians in 1950 and 1960. This was true for their ordinary least squares estimate as well as the two-stage least squares model in which the failure rate was included in the supply equation. The authors hypothesized that states which have a high number of physicians may either be in a position to impose higher standards or are particularly attractive to physicians who are likely to fail the examination. 
Scheffler found a negative relationship between failure rate and per capita availability of physicians. These findings were not statistically significant, however, for any of the five physician categories studied. The five physician types were medical specialists, surgical specialists, general practitioners, interns, and residents.

\section{Training Facilities}

The availability of medical school training facilities was considered as a factor influencing the location of physicians by Benham et al. The authors used the total number of seats in state medical schools as a proxy for the nonpecuniary amenities available in a state, and found a consistent positive relationship between the number of seats and the number of physicians in all years studied (1930, 1940, 1950, 1960). The relationship was statistically significant in the years 1930 and 1960 . When both variables were considered on a per capita basis the relationship was statistically significant for all four years. Scheffler found the number of freshman class medical school seats to be positively related to per capita availability of surgical specialists, medical specialists, general practitioners, residents, interns and the aggregate of all groups. Except for general practitioners the relationship was highly significant.

\section{Hospital Beds}

An additional measure of the advantages of practicing in a particular state is the availability of hospital facilities. Hospitals constitute, in effect, capital goods which are utilized by physicians at no charge. ${ }^{3}$ Scheffler reported a strong positive relationship between beds and the number of physicians per capita. The availability of hospital beds was statistically significant for all physician categories except general practitioners.

\section{EMPIRICAL Results}

Having examined the results reported in previous studies of the distribution of physicians, we find that there is no general agreement on the impact of physician earnings, area per capita income, and licensure procedures upon the locational decisions of physicians. There is some consensus on the influence of urbanization, population, and the availability of professional amenities (e.g., medical schools and hospitals); yet, the empirical results even with these variables have not always been consistent.

\section{Cross-sectional Regressions}

In order to further examine the factors influencing the regional distribution of physicians, variations of the following equation were fitted to statewide data for 1967 and 1968:

$$
\begin{aligned}
\mathrm{MD}_{\mathrm{i}}= & \mathrm{A}_{\mathrm{o}}+\mathrm{A}_{1} \mathrm{EARN}_{\mathrm{i}}+\mathrm{A}_{2} \mathrm{INC}_{\mathrm{i}}+\mathrm{A}_{3} \mathrm{GRAD}_{\mathrm{i}}+\mathrm{A}_{4} \mathrm{URBN}_{\mathrm{i}} \\
& +\mathrm{A}_{5} \mathrm{BARR}+\mathrm{A}_{6} \text { BEDS }_{\mathrm{i}}+\mathrm{U}_{\mathrm{i}}
\end{aligned}
$$


where,

$\mathrm{MD}_{\mathrm{i}}=$ Number of active, non-federal physicians per capita in the i th state.

$\mathrm{EARN}_{\mathrm{i}}=$ Average earnings of sole proprietorship physicians from professional practice in the $\mathrm{i}$ th state.

$\mathrm{INC}_{\mathrm{i}}=$ Personal per capita income in the $\underline{\mathrm{i}}$ th state.

$\mathrm{GRAD}_{\mathrm{i}}=$ Number of MD graduates in the $\underline{\mathrm{i}}$ th state per capital.

$\mathrm{URBN}_{\mathrm{i}}=$ Percentage of persons living in metropolitan areas in the $\mathrm{i}$ th state.

BARR $_{\mathrm{i}}=$ Percentage of applicants passing the state medical examination in the $\underline{i}$ th state.

BEDS $_{\mathrm{i}}=$ Per capita number of short-term general and specialty hospital beds in the $\underline{i}$ th state.

$\mathrm{U}_{\mathrm{i}}=\mathrm{A}$ stochastic term.

A complete description of the variables along with the data sources is given in the Appendix. The sample for this study consists of observations for 36 states in 1968 and 31 states in $1967 . .^{4}$ Most of the omitted states have small populations, and their absence has little effect on the results reported here because each observation in the sample was weighted by the square root of the state population. ${ }^{5}$ The states included in this analysis accounted for more than 90 percent of the total U.S. population.

The results are shown in Table $1 .{ }^{6}$ In interpreting these results the usual precautions apply, i.e., a single equation model is merely descriptive and ignores interrelationships which might reasonably be expected to determine several of the variables in the system. Two simple structural models which attempt to capture some of the more obvious interactions are presented in a following section. The results presented in Table 1 are, however, interesting by way of contrast with those reported by previous studies which did not have adequate data on the earnings of physicians. Furthermore, investigations of the regional distribution of physicians are typically limited by problems of multicollinearity and, as a result, the independent effects of all variables cannot always be calculated with confidence. Essentially the only solution to the multicollinearity deadlock is the acquisition of additional data that allows for more variation among the independent variables; therefore, the additional results presented here constitute a new sample that offers new evidence on the forces that influence the location of physicians.

As shown in Table 1, per capita personal income, the per capita number of M.D. graduates, and the degree of urbanization are the three variables most strongly associated with the per capital number of physicians. The significance of the income and urbanization variables is consistent with the results reported in previous studies, and generally supports the proposition that physicians tend to concen- 
TABLE 1

Cross-Sectional Regressions of Per Capita Number of Physicians

\begin{tabular}{|c|c|c|c|c|c|c|c|c|c|}
\hline \multirow[b]{2}{*}{ Year } & \multirow[b]{2}{*}{ Constant } & \multicolumn{5}{|c|}{ Coefficient, t-Value, and Elasticity at the Mean of } & \multirow[b]{2}{*}{ BEDS $_{i}$} & \multirow[b]{2}{*}{$\mathrm{R}^{2}$} & \multirow[b]{2}{*}{$\mathrm{N}$} \\
\hline & & $\mathrm{EARN}_{\mathrm{i}}$ & $\mathrm{INCM}_{\mathrm{i}}$ & $\mathrm{GRAD}_{\mathrm{i}}$ & $\mathrm{URBN}_{\mathbf{i}}$ & BARR & & & \\
\hline 1967 & $\begin{array}{l}-0.0007927 * * \\
(-1.9087)\end{array}$ & $\begin{array}{l}-0.00000000726 \\
(-0.8618) \\
-0.222\end{array}$ & $\begin{array}{l}0.0000005427^{*} \\
(3.0649) \\
1.35\end{array}$ & $\begin{array}{l}11.6973 \% \\
(3.6784) \\
0.384\end{array}$ & $\begin{array}{l}0.000002380 \\
(0.5201) \\
0.352\end{array}$ & $\begin{array}{l}-.00000131918 \\
(-1.7025) \\
-0.104\end{array}$ & $\begin{array}{l}0.0047128 \\
(0.0539) \\
0.105\end{array}$ & 0.705 & $\overline{31}$ \\
\hline 1968 & $\begin{array}{l}0.0001852 \\
(0.5097)\end{array}$ & $\begin{array}{l}-0.00000000988 \\
(-1.1490) \\
-0.244\end{array}$ & $\begin{array}{l}0.0000002337 * * \\
(2.0198) \\
0.617\end{array}$ & $\begin{array}{c}1.6965 \\
(0.9506) \\
0.053\end{array}$ & $\begin{array}{l}0.000007127 * * \\
(2.3560) \\
0.118\end{array}$ & $\begin{array}{l}-0.000001400 \\
(-0.8788) \\
-0.086\end{array}$ & $\begin{array}{c}0.04007 \\
(0.7248) \\
0.122\end{array}$ & 0.7619 & 36 \\
\hline $\begin{array}{l}1967-68 \\
\text { Pooled }\end{array}$ & $\begin{array}{l}-0.0002825 \\
(-1.0602)\end{array}$ & $\begin{array}{l}-0.000000007867 \\
(-1.3021) \\
\quad-.234\end{array}$ & $\begin{array}{l}0.0000003363 * \\
(3.4997) \\
0.882\end{array}$ & $\begin{array}{l}4.8469 * \\
(2.7866) \\
0.156\end{array}$ & $\begin{array}{l}0.000005634 * * \\
(2.1581) \\
0.282\end{array}$ & $\begin{array}{l}-.00000163996 \\
(-0.1767) \\
-0.116\end{array}$ & $\begin{array}{c}0.03233 \\
(0.6197) \\
0.133\end{array}$ & 0.6558 & 67 \\
\hline 1967 & $\begin{aligned} & 0.0007792 * * \\
&(-2.3980)\end{aligned}$ & $\begin{array}{l}-0.00000000731 \\
(-0.8912) \\
-0.222\end{array}$ & $\begin{array}{l}0.0000005278 * \\
(3.3395) \\
1.32\end{array}$ & $\begin{array}{l}11.7689 * \\
(4.1570) \\
0.387\end{array}$ & $\begin{array}{l}0.000002294 \\
(0.5462) \\
0.116\end{array}$ & $\begin{array}{l}-.00000127295 * \\
(-1.7741)\end{array}$ & & 0.7046 & 31 \\
\hline 1968 & $\begin{array}{l}0.0003183 \\
(1.02351)\end{array}$ & $\begin{array}{l}-0.0000000108 \\
(-1.2769) \\
-0.244\end{array}$ & $\begin{array}{l}0.0000002577 * * \\
(2.3437) \\
0.698\end{array}$ & $\begin{array}{l}2.30998 \\
(1.4819) \\
0.073\end{array}$ & $\begin{array}{l}0.000006394 * * \\
(2.2607) \\
0.316\end{array}$ & $\begin{array}{l}-0.000001410 \\
(-0.8930) \\
-0.087\end{array}$ & & 0.7576 & 36 \\
\hline $\begin{array}{l}1967-68 \\
\text { Pooled }\end{array}$ & $\begin{array}{l}-0.0001831 \\
(-0.8649)\end{array}$ & $\begin{array}{l}-0.00000000836 \\
(-1.4023) \\
-0.234\end{array}$ & $\begin{array}{l}0.0000003557^{*} \\
(3.9363) \\
0.934\end{array}$ & $\begin{array}{l}5.3368 * \\
(3.4618) \\
0.172\end{array}$ & $\begin{array}{l}0.000005065 * * \\
(2.0832) \\
0.255\end{array}$ & $\begin{array}{l}-.00000238629 \\
(-0.2606) \\
-0.169\end{array}$ & & 0.6536 & 67 \\
\hline 1967 & $\begin{array}{l}-0.0006430 * * \\
(-1.9572)\end{array}$ & $\begin{array}{l}-0.00000000453 \\
(-1.1732) \\
-0.111\end{array}$ & $\begin{array}{l}0.0000003803 * \\
(2.7193) \\
0.96\end{array}$ & $\begin{array}{l}9.8361^{*} \\
(3.6177) \\
0.323\end{array}$ & $\begin{array}{l}0.000007025 * * \\
(2.0814) \\
0.357\end{array}$ & & & 0.6673 & 31 \\
\hline 1968 & $\begin{array}{l}0.0002007 \\
(0.7147)\end{array}$ & $\begin{array}{l}-0.0000000133 \\
(-1.6886) \\
-0.244\end{array}$ & $\begin{array}{l}0.0000002908 * \\
(2.8181) \\
0.778\end{array}$ & $\begin{array}{c}2.4237 \\
(1.5651) \\
0.077\end{array}$ & $\begin{array}{l}0.000006053^{* * *} \\
(2.1671) \\
0.299\end{array}$ & & & 0.7511 & 36 \\
\hline $\begin{array}{l}1967-68 \\
\text { Pooled }\end{array}$ & $\begin{array}{l}-0.0001766 \\
(-0.8465)\end{array}$ & $\begin{array}{l}-0.00000000814 \\
(-1.3899) \\
-0.234\end{array}$ & $\begin{array}{l}0.0000003470 * \\
(4.1617) \\
0.908\end{array}$ & $\begin{array}{l}5.2167^{*} \\
(3.5729) \\
0.168\end{array}$ & $\begin{array}{l}0.000005365^{*} \\
(2.5261) \\
0.269\end{array}$ & & & 0.6532 & 67 \\
\hline
\end{tabular}


trate in urbanized upper income areas where the ability to pay for medical care is high and where the amenities of urban practice are available. The significance of the per capita number of M.D. graduates is also consistent with previous studies, and demonstrates the importance of professional amenities in the physician's locational choice. It is interesting to note that even though these variables are significant, their impact upon the physician-population ratio as measured by the calculated elasticities, is rather small. All but two of the elasticities, evaluated at the means of the variables, are in the inelastic range.

The per capita number of hospital beds and the percentage of applicants passing the state medical examination were not consistently significant in these regressions. The failure of the hospital facilities variable to be a significant determinant of the per capita number of physicians conflicts with the results reported by Scheffler using pooled state data for 1963 and 1967. It is likely that much of the impact of the hospital facilities variable $\left(\mathrm{BEDS}_{\mathbf{i}}\right)$ is captured by the variable GRAD $_{i}$, since in our sample these two variables moved together. ${ }^{7}$ However, in view of the well-known dangers of generating spurious relationships when the variation among independent variables is small, we shall not speculate further upon this result but merely report it. The nonsignificance of barriers to practice variable $\left(\mathrm{BARR}_{\mathrm{i}}\right)$ is explicable both in terms of previous studies and on general a priori grounds. As indicated in the previous section, the percentage of applicants passing the state licensure examination is a rather weak measure of the barriers to physician mobility, and there is strong evidence that the pass rates vary widely from year to year within states as the judgements of examiners change [10]. Moreover, there is widespread interstate reciprocity in licensing physicians so that the relevant barriers to physician mobility are not policy created, but are inherent because of inertia.

The average earnings of physicians was also insignificant as a determinant of the physician-population ratio, and the sign of the estimated coefficient was consistently negative. The basic difficulty here is that both the quantity and the earning of physicians are, in principle, determined by the other exogenous variables in the model. In a following section, when both the quantity and earnings of physicians are considered as endogenous variables in a simultaneous equation model, the earnings of physicians is shown to be a strong determinant of the physician-population ratio. The negative estimated coefficient for EARN $_{\mathrm{i}}$ shown in Table 1 should not be interpreted as implying that physicians respond in a perverse way to differential earnings. In fact, the negative sign is exactly what one would expect if market forces were redirecting physicians away from areas where the physician-population ratio was high. The disappointing result here is the relative smallness of the calculated coefficient of elasticity, indicating that physicians tend to be rather unresponsive to earning differentials. And, consequently, rather large swings in physicians' income or substantial income supplements would be necessary in order to redirect physician manpower.

\section{Structural Relations}

Previous attempts by economists [8] [15], to analyze the distribution of physicians have generally conceived of the stock of physicians as being jointly 
determined by the workings of the forces of supply and demand. Physicians are usually hypothesized to respond directly to the availability of professional and personal amenities generally afforded in high income, urbanized areas, and to the likelihood of higher earnings. Consumers of physician services are likewise usually assumed to respond positively to income and negatively to price. The demand for physician services is usually assumed to be income elastic and price inelastic. ${ }^{8}$ Utilizing this type of approach, i.e., that of neoclassical economic theory, the consumer is viewed as a person demanding physician services because of a characteristic of himself, his family, and his environment. This type of approach hypothesizes a population of consumers perfectly informed concerning contemporary standards of good health, the health status of other consumers and the powers of modern medicine. However, it is not at all clear that neoclassical theory can be made to apply to a "market" for physicians. In this section, therefore, we develop and estimate two different structural models relevant to the determination of the spatial distribution of physicians. The first hypothesizes the normal supply and demand functions of physicians, while the second is based upon a view of the physician as both a supplier and a purchaser of medical services for the patient.

\section{(A) A Supply and Demand Model for Physicians}

The simple supply and demand model which we have estimated contains two equations, one each for the supply and the demand function. It can be written as follows: ${ }^{9}$

(2) Demand: $\mathrm{MD}_{\mathrm{i}}{ }^{*}=\mathrm{D}_{\mathrm{o}}+\mathrm{D}_{1}$ EARN $_{\mathrm{i}}^{*}+\mathrm{D}_{2} \mathrm{INCM}_{\mathrm{i}}+\mathrm{U}_{2}$

(3) Supply: $\mathrm{MD}_{\mathrm{i}}{ }^{*}=\mathrm{S}_{\mathrm{o}}+\mathrm{S}_{1} \mathrm{EARN}_{\mathrm{i}}{ }^{*}+\mathrm{S}_{2} \mathrm{GRAD}_{\mathrm{i}}+\mathrm{S}_{3} \mathrm{URBN}_{\mathrm{i}}+\mathrm{U}_{3}$

*Denotes an endogenous variable.

All variables are defined as in equation 1 of the previous section. Both equations are identified; the supply equation is exactly identified, and the demand equation is over-identified. The expected signs of the coefficients of this model are those of a traditional supply and demand system. The coefficients of all variables are assumed a priori to be positive except the coefficient of EARN $\mathrm{i}_{\mathrm{i}}$ in equation 2. The negative sign for $\mathrm{D}_{1}$ in equation 2 is expected, of course, because certerius paribus low average physician earnings result from lower fees and/or smaller quantities sold per physician which leads to the per capita demand for a higher number of physicians.

Table 2 shows the coefficients estimated for this model utilizing the twostage least squares regression technique. The estimates are based upon a pooled sample of states for 1967 and $1968 .^{10}$ The signs of the estimated coefficients reported in Table 2 all correspond to theoretical expectations. The coefficient of EARN $_{\mathrm{i}}$ is negative in the demand equation and positive in the supply equation. The price elasticity estimated in the demand equation corresponds to that estimated in other empirical studies of the demand for health care which have generally shown that the price elasticity is less than one. The responsiveness of physicians 
to earning differentials is relatively high, judging on the basis of the calculated price elasticity in the supply equation. This result would appear to indicate that relatively small increases in physician earnings or income supplements could markedly affect the present allocation of physicians among the various states and regions. It is interesting to note that this result contrasts sharply to that suggested by the ordinary least squares regression presented in the previous section.

A particularly interesting aspect of this model is that the signs of the estimated coefficients correspond to theoretical expectations. On the basis of these results, it appears that perhaps the concept of a market for physicians is not altogether useless even though the price responsiveness of consumers in the market is quite low. These results appear to suggest that the economist's concept of a shortage of physicians might be satisfied by letting the price of physician services and physician earnings be bid upward until the market is cleared.

Unfortunately, the medical profession has done very little to facilitate an adequate flow of consumer information on physician quality and availability. It has, in fact, erected formidable barriers to direct competition among physicians [9]. This means that not only is competitive pricing of physician services absent, but that the supply of health services provided by physicians is not based on anything analogous to long-run marginal cost. If effective price competition could be instituted, then the empirical estimates of this model indicate that the price mechanism could be made to function in a market for physicians.

\section{(B) The Physician as Both Supplier and Consumer}

As an alternative to the conceptual framework outlined above, there are strong reasons which suggest that physicians cannot be treated as suppliers of normal services which are subject to the forces of supply and demand. The basic reason for this is that the physician normally acts as both supplier of medical services and purchasing agent of these services for his patient. In other words, the physician normally acts not only on behalf of his own interest but also on behalf of the interests of his patients as well. This occurs simply because the patient, not possessing the requisite medical knowledge, often does not know and cannot determine the quantity of physician services required. The physician is therefore placed in a position in which he is able to create his own demandthe physician, as an expert, commonly dictates to the consumer what he shall buy and the consumer commonly follows the dictates of his physician. Paul J. Feldstein $[6, p .152]$ has sketched this view of physician behavior and has concluded, “. . . the physician knows the patients' needs and financial resources and, other things being equal, he acts as a purchaser for the patient . . . the physician is making the decisions that the patient would make if he had knowledge to do so."

Accepting this view of physician behavior implies, of course, that the traditional concept of a market demand schedule for physicians' services constructed through an aggregation of the independent demand functions of individual consumers is no longer meaningful. Instead, it needs to be replaced by what we shall refer to as an aggregate potential earnings function for physicians. We posit such a potential earnings schedule in which the average earnings of physicians are 
functionally determined by per capita income, the per capita number of physicians in the area, and barriers to physician entry. We combine this potential earnings schedule with a second equation describing the per capita number of physicians in an area. This second equation posits that the per capita number of physicians is functionally related to average earning, the per capita number of M.D. graduates, and the degree of urbanization. The complete model can be written as follows:

(4) Potential Earnings:

(5) Geographic Location:

$$
\begin{aligned}
& \text { EARN }_{\mathrm{i}}^{*}=\mathrm{E}_{\mathrm{o}}+\mathrm{E}_{1} \mathrm{MD}_{\mathrm{i}}^{*}+\mathrm{E}_{2} \text { BARR }_{\mathrm{i}} \\
& +\mathrm{E}_{3} \mathrm{INCM}_{\mathrm{i}}+\mathrm{U}_{\mathrm{E}} \\
& \mathrm{MD}_{\mathrm{i}}^{*}=\mathrm{G}_{\mathrm{o}}+\mathrm{G}_{1} \text { EARN }_{\mathrm{i}}^{*}+\mathrm{G}_{2} \text { GRAD }_{\mathrm{i}} \\
& +\mathrm{URBN}_{\mathrm{i}}+\mathrm{U}_{\mathrm{G}}
\end{aligned}
$$

*Denotes an endogenous variable.

The variables are again defined as previously. Both equations are over-identified.

The rationale for the expected signs in the potential earnings equation is simple. It is expected that average earnings are negatively related to per capita number of MD's for the following reason: everything else being equal, larger numbers of physicians per capita result in smaller quantities of services sold per physician and/or lower fees which lead to lower average earnings. It is expected that the effect of the per capita number of physicians upon average earnings will be small since competition among physicians is minimal, and the physician is to a great extent able to create his own demand subject only to the budget constraint of his patient. When physicians are abundant in a state, they may order care which is not medically indicated (e.g., unnecessary surgery) or care which is only of marginal importance (e.g., cosmetic procedures, numerous postoperative visits, overzealous well-baby care). Alternatively, when physicians are relatively scarce, they may lower their standards and may refuse to handle many minor complaints. Per capita income serves as a proxy for the financial resources of the average patient, and it is expected that average physician earnings will be greater where the average patient's ability to pay for medical care is high. Finally, barriers to entry are expected to provide a positive stimulus to physician earnings (i.e., the sign of the coefficient BARR $_{i}$ is expected to be negative).

The rationale of the function describing geographic location is also fairly obvious. As the supply equation estimated in the previous section, the per capita number of physicians is assumed to be positively related to average earnings, the per capita number of M.D. graduates, and the degree of urbanization. The vari-

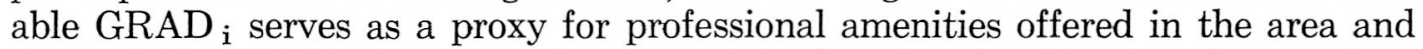
the variable $\mathrm{URBN}_{\mathrm{i}}$ is a proxy for the social, educational, cultural, and recreational attributes of the community. Urban areas are assumed to offer the physician a wider variety of cultural and recreational facilities, as well as the opportunity to associate with a more educated clientele. 
The results of estimating this system of equations by means of two-stage least squares is shown in Table 3. The model performs fairly well, and all of the variables have the expected signs except the coefficient of BARR $R_{i}$. Physicians are again shown to be relatively responsive to earnings differentials, as measured by the calculated elasticity of the earnings variable in the equation for geographic location. However, physician earnings are relatively unresponsive to both per capita income, and the number of physicians per capita. The inelasticity of physician earnings with respect to the number of physicians per capita was expected because of the limited competition among physicians. This result also supports our hypothesis regarding the ability of the physician, acting as an agent for his patients, to create a demand for his own services.

The inelasticity of physician earnings with respect to per capita income was not expected, and, indeed, is quite surprising. This result appears to indicate that physicians are not charging fees and prescribing medical care so as to maximize their own earnings. Since, in this model, the physician acts not only in his own interest but in the interests of his patients as well, this result suggests that the physician does, perhaps, ignore his own interest in deference to the interests of his patients. ${ }^{11}$

\section{CONCLUSION}

The reports of current and impending crisis in the physician care delivery system, particularly the repeated assertions of a national shortage of physician manpower, insure that the distribution of physicians will continue as an issue of major public concern well into the next decade. In a normative sense, there is no doubt that the geographic distribution of active physicians and physicians' services is uneven, and that large segments of the U.S. population find it difficult to secure the services of a physician. This paper has of necessity been limited to a rather narrow range of issues. We have attempted to evaluate the magnitude and direction of the major forces shaping the current geographic placement of physicians in the U.S. Our results confirm previous research and general lay opinion regarding the propensity of physicians to concentrate in high income, urban areas where the ability to pay for physicians' services is large and the professional and personal amenities of private practice are high.

We have also made some progress in delineating the structural relationships which produce this concentration. A simple supply and demand model for physicians' services was estimated which performed relatively well. The estimated price and income elasticities of demand for physician services both correspond to theoretical expectations. In addition, the quantity of physicians per capita supplied in an area was shown to be highly responsive to expected earnings, even though it should be acknowledged that the speed of adjustment may be quite slow because the principle migrants are the new entrants into the profession $[8$, p. 175] [19, p. 188].

Although the empirical estimates of the demand and supply model correspond to theoretical expectations, there are strong a priori reasons for assuming 
TABLE 2

Two-Stage Least-Squares Estimates of Supply and Demand Equations of Physicians, 1967-68

\begin{tabular}{|c|c|c|c|c|c|c|c|}
\hline \multirow{2}{*}{$\begin{array}{l}\text { Dependent } \\
\text { Variable }\end{array}$} & \multicolumn{6}{|c|}{ Coefficient, t-Ratio, and Elasticity at the Mean of } & \\
\hline & Constant & $\mathrm{EARN}_{\mathrm{i}}$ & $\operatorname{INCM}_{i}$ & GRAD $_{i}$ & $\mathrm{URBN}_{\mathrm{i}}$ & $\mathrm{N}$ & \\
\hline $\mathrm{MD}_{\mathrm{i}}$ & $\begin{array}{l}0.0001705 \\
(0.3618)\end{array}$ & $\begin{array}{l}-0.00000002279 \\
(-1.2437) \\
-0.467\end{array}$ & $\begin{array}{l}0.0000005359 \\
(8.4545) \\
1.40\end{array}$ & & & 67 & Demand \\
\hline $\mathrm{MD}_{\mathrm{i}}$ & $\begin{array}{l}-0.001663 \\
(-1.7908)\end{array}$ & $\begin{array}{l}0.00000006740 \\
(2.0606) \\
1.64\end{array}$ & & $\begin{array}{c}3.8651 \\
(1.2964) \\
0.125\end{array}$ & $\begin{array}{l}0.00001368 \\
(5.3165) \\
0.684\end{array}$ & 67 & Supply \\
\hline
\end{tabular}

TABLE 3

Two-Stage Least-Squares Estimates of the Distribution of Physicians, 1967-68

\begin{tabular}{|c|c|c|c|c|c|c|c|c|c|}
\hline \multirow{2}{*}{$\begin{array}{l}\text { Dependent } \\
\text { Variable }\end{array}$} & \multicolumn{8}{|c|}{ Coefficient, t-Ratio, and Elasticity at the Mean of } & \\
\hline & Constant & EARN $_{i}$ & $\mathrm{MD}_{\mathrm{i}}$ & GRAD $_{i}$ & BARR $_{i}$ & $\mathrm{URBN}_{\mathrm{i}}$ & $\mathrm{INCM}_{\mathbf{i}}$ & $\mathrm{N}$ & \\
\hline $\mathrm{EARN}_{\mathrm{i}}$ & $\begin{array}{r}22146.5 \\
(5.9667)\end{array}$ & & $\begin{array}{l}-0.00000003978 \\
(-1.5968) \\
-0.00\end{array}$ & & $\begin{array}{l}.000001012 \\
(0.6124) \\
0.071\end{array}$ & & $\begin{array}{c}3.4159 \\
(2.0167) \\
0.379\end{array}$ & 67 & $\begin{array}{l}\text { Potential } \\
\text { Earnings }\end{array}$ \\
\hline $\mathrm{MD}_{\mathrm{i}}$ & $\begin{array}{l}-0.001408 \\
(-1.7852)\end{array}$ & $\begin{array}{l}0.00000005820 \\
(2.1033) \\
1.45\end{array}$ & & $\begin{array}{c}4.2359 \\
(1.5173) \\
0.136\end{array}$ & & $\begin{array}{l}0.00001350 \\
(5.7674) \\
0.676\end{array}$ & & 67 & $\begin{array}{l}\text { Geographic } \\
\text { Location }\end{array}$ \\
\hline
\end{tabular}


that the demand for physicians is not independent of supply. Indeed, to a major extent, physicians have the ability to create their own demand. Accordingly, we have estimated a second structural model in which the demand relation is replaced by a potential earnings function for physicians. This approach does not require that markets clear, but merely that potential physician earnings and the quantity of physicians per capita be jointly determined. Empirical estimates of this model also perform relatively well, and the estimated relations are consistent with theoretical expectations. Estimates here indicate that physicians are relatively responsive to expected earnings and that their expected earnings are little affected by the number of physicians per capita.

Unfortunately, available data do not allow us to choose between these two models. What we have shown is that both may be regarded as alternative explanations of the structural forces shaping the distribution of physicians. Both of the estimated structural models indicate that some form of income supplements might be considered as a means of enticing physicians to establish practice in areas which are under supplied with physicians. ${ }^{12}$ In addition, since professional amenities play an important role in the physician's locational decision, it is obvious that a regional perspective needs to be maintained in the establishment of both medical educational facilities and general health infrastructure.

\section{APPENDIX}

\section{Definitions and Data Sources}

BARR $_{i} \quad$ The probability of passing the medical licensure examination in the i th state. Where applicable this was the joint probability of passing the basic science examination and the medical licensure examination. Data for BARR $_{i}$ were found in [12].

BEDS $_{i} \quad$ The per capita number of short term general and specialty hospital beds in the $\underline{i}$ th state. Total number of beds data were taken from [21]. Population data were taken from [20].

EARN $_{i} \quad$ Average earnings of sole proprietoriship physicians from professional practice in the i th state. Data were taken from [23].

GRAD $_{\mathrm{i}} \quad$ Number of M.D. graduates per capita in the $\underline{i}$ th state. Total graduate data were taken from [11]. Population data were taken from [20].

$\mathrm{INC}_{\mathbf{i}} \quad$ Personal per capita income in the $\underline{i}$ th state. $\mathrm{INC}_{\mathbf{i}}$ was in [21].

$\mathrm{MD}_{\mathrm{i}} \quad$ Number of active, non-federal physicians per capita in the $\underline{i}$ th state. Total number of physicians per state was found in [12]. Population data were taken from [20].

1This is evidenced by the fact that recent research on the distribution of physicians have either deleted physician income entirely from the analysis or have used very limited data. The former approach was adopted by R. M. Scheffler [17] in his analysis of the interstate distribution of physicians. Henry B. Steele and 
Gaston V. Rimlinger [19] utilized physician income data applicable to 19 standard metropolitan areas in 1949. L. Benham, A. Maurizi, and M. W. Reder [3] utilized a vaguely defined concept described as medics' income, but these data could not be located from the sources listed in their article. The term "medics" is never clearly defined in the article but is thought to include physicians, osteopaths, dentists, and others.

2The earnings data utilized in this investigation have been made available only recently by the Internal Revenue Service [23]. The accuracy of this earning series is not easy to check. There is reason to believe that underreporting by medical professional personnel may bias this series downward. The resultant bias, however, is most likely no larger than that in data based upon the tax returns of other self-employed professionals and small businessmen who have many small cash paying clients. Furthermore, only if the degree of underreporting varied significantly across states would this factor impair the validity of the analysis.

3For a theoretical justification of this view, see Mark Pauly and Michael Redisch [13].

4The 36 states included in the sample for 1968 were: Alabama, Arizona, Arkansas, California, Colorado, Connecticut, Florida, Georgia, Illinois, Indiana, Iowa, Kansas, Kentucky, Louisiana, Maine, Maryland, Massachusetts, Michigan, Minnesota, Mississippi, Missouri, Nebraska, New Jersey, New York, North Carolina, Ohio, Oklahoma, Oregon, Pennsylvania, South Carolina, Tennessee, Texas, Virginia, Washington, Wisconsin and West Virginia. Complete data were not available for five of these states in 1967, and consequently they were deleted from the 1967 sample. The five states were: Arkansas, Kansas, Maine, Mississippi, and South Carolina.

5This weighting procedure was adopted to avoid problems of heteroscedasticity. Plots of the residuals from unweighted regressions demonstrated an inverse relationship between population and the size of the unexplained residual.

6It might be suspected that there are other variables than those included in equation 1 which influence physicians' locational decisions; however, early experiments which we conducted failed to reveal these variables. Nine additional variables - most of which fall under the heading of personal and professional amenities of practice in an area-were tested in preliminary versions of the model. The rejected variables were: education (median years of school of persons 25 and over), two measures of insurance coverage (percentage of persons with private or group coverage and group and private insurance premiums per capita), two measures of health status (the infant mortality rate and the crude death rate), per cent black, per cent female, per cent over 65 years of age and mean annual temperature.

${ }^{7}$ In our sample, the simple correlation coefficient between BEDS $_{i}$ and GRAD $_{i}$ was 0.55 for $1967,0.66$ for 1968 , and 0.49 in the pooled sample.

8 For some empirical estimates of the price and income elasticities of the demand for medical care, see for example, P. J. Feldstein [7] and G. D. Rosenthal [16].

${ }^{9} \mathrm{As}$ is the case with equation 1 , one might suspect that other additional variables should be included in a system of equations describing the supply and demand for physicians. Again, however, early experiments in which we tried to introduce additional variables into the model failed to enhance the performance of the model.

10The technique of pooling data is discussed in James L. Murphy, Introductory Econometrics. (Homewood, Ill., Richard D. Irwin, Inc., 1973), pp. 355-57.

${ }^{11}$ The absence of profit maximizing behavior as a result of the influences similar to those discussed above has been noted by Kenneth Arrow. He states, "one consequence of such trust relations is that the physician cannot act, or at least appear to act, as if he is maximizing his income at every moment of time. . ." [2, p. 965].

12 Because of the restrictions imposed by the medical profession upon the flow of consumer information and the lack of price competition among physicians, a policy of income supplements or differential tax treatment for physicians practicing in areas of low physician availability probably has the same basis in equity as a negative excess profits tax. However, from a pragmatic standpoint, it is perhaps the only way to insure a reasonably equitable distribution of physicians throughout the country.

\section{REFERENCES}

1. American Medical Association, Department of Survey Research. Distribution of Physicians, Hospitals, and Hospital Beds in the U.S., Chicago, (1970).

2. Arrow, Kenneth J. "Uncertainty and the Welfare Economics of Medical Care," American Economic Review, Vol. LIII (December 1963), p. 941-973.

3. Benham, L., A. Manrizi, and M. W. Reder, "Migration, Location and Remuneration of Medical Personnel: Physicians and Dentists," Review of Economics and Statistics, Vol. L (August 1968), pp. 332-347.

4. Charles, Ed. "Policies to Increase the Supply of Physicians in Rural Communities," The American Economist (Fall 1972), pp. 36-40.

5. Feldstein, Martin S. "The Rising Price of Physicians' Services," The Review of Economics and Statistics, Vol. LII (May 1970), pp. 121-133.

6. Feldstein, Paul J. "Research on the Demand for Health Services," Milbank Memorial Fund Quarterly, Vol. XLIV (July 1966), pp. 128-162.

7.

"The Demand for Medical Care," In: The Commission on the Cost of Medical Care. General Report, Vol. I., Chicago (1964). 
8. Friedman, Milton, and Simon Kuznets, Income from Independent Professional Practice, New York: National Bureau of Economic Research (1945).

9. Kessel, Reuben A. "Price Discrimination in Medicine," The Journal of Law and Economics, Vol. 1 (October 1958), pp. 20-53.

10. Letsou, Vasilios G. "Problems of Medical Licensure," The Journal of the American Medical Association, Vol. 210 (December 1, 1969), p. 1764.

11. "Medical Education," Journal of the American Medical Association, Volumes 202, 204, 206.

12. "Medical Licensure Statistics," Journal of the American Medical Association, Volumes 204, $206,208$.

13. Pauly, Mark and Michael Redisch, "The Not-For-Profit Hospital as a Physicians' Cooperative," American Economic Review, Vol. LXIII (March 1973), pp. 87-99.

14. Rayack, E. “The Supply of Physicians' Services," Industrial and Labor Relations Review, Vol. 17 (January 1964), pp. 221-237.

15. Rimlinger, Gaston V. and Henry B. Steele, "An Economic Interpretation of the Spatial Distribution of Physicians in the U.S.," Southern Economic Journal (July 1963), pp. 1-12.

16. Rosenthal, G. D. "Price Elasticity of Demand for Short Term General Hospital Services," In: Klarman, H. E. (ed.). Empirical Studies in Health Economics, Baltimore, (1970).

17. Scheffler, R. M. "The Regional Distribution of Physicians and Specialists," The Review of Regional Studies, Vol. II (Winter 1972), pp. 63-80.

18. Sloan, Frank A. "Lifetime Earnings and Physicians' Choice of Specialty," Industrial and Labor Relations Review, Vol. 24 (October 1970), pp. 47-56.

19. Steele, Henry B. and Gaston V. Rimlinger, "Income Opportunities and Physician Location Trends in the United States," Western Economic Journal, (Spring 1965), pp. 182-194.

20. U. S. Department of Commerce, Bureau of the Census. Current Population Reports, Series p. 25, No. 420, Washington, D. C. (April 17, 1969).

21. U. S. Department of Commerce, Bureau of the Census. Statistical Abstract of the United States, various volumes.

22. U. S. Department of Health, Education, and Welfare. Health Manpower: A County Metropolitan Data Book, Washington, D. C., various volumes.

23. U. S. Department of Health, Education and Welfare. Income of Physicians, Osteopaths and Dentists from Professional Practice: 1965-1969, Staff Paper No. 12, Washington, D. C. (1972). 